\title{
Community Mental Health Journal and the Covid19 Pandemic
}

\section{Sandra Steingard ${ }^{1}$}

Published online: 11 August 2020

(c) Springer Science+Business Media, LLC, part of Springer Nature 2020

When I became Editor-in-Chief of the Community Mental Health Journal, I had hoped that, in addition to continuing to publish research articles pertinent to our field, we could also provide a forum where innovative and emerging practices could be introduced. We introduced a format, Fresh Focus, which allows for such discourse.

Of course, we could not have anticipated Covid19. The pandemic poses a multitude of challenges for all of us. In the world of journal editing, one of them is balancing the demands of scientific rigor with the importance of rapid dissemination of information to readers. I am pleased that, in this issue, we have a series of articles that demonstrates how we are addressing this tension and hope to continue to do so in the future.

The first paper is a brief report by Reyes and colleagues, titled, Promoting Resilience Among College Student Veterans Through an Acceptance-and-Commitment-Therapy App: An Intervention Refinement Study (https://doi.org/10.1007/ s10597-020-00617-4). This reports the introduction of a digital application that was designed to engage veterans in Acceptance and Commitment Therapy (ACT). There are many aspects of this article that are aligned with the values of the Journal: The researchers engaged their subjects in a collaborative process to evaluate the intervention; the application was considered in a non-pathologizing way as a means of promoting resilience; and it was designed to engage a population whose members are often reluctant to seek help.

In response to that article is a Fresh Focus paper by Alexandros and colleagues, The Use of Digital Applications and
COVID-19 (https://doi.org/10.1007/s10597-020-00689-2). That group has also published in this area and wondered if this approach could be expanded to include health care workers and others who are exposed to trauma in their roles on the front lines of the pandemic. It was heartening that in their article, they cite the innovative work by Cheng and colleagues, reported in our first Fresh Focus article, on use of an online application to create a forum that provided support to front-line workers who were the first to encounter Covid19 in Wuhan, China (Cheng P, Xia G, Pang P, Wu B, Jiang W, Li Y, et al. COVID-19 epidemic peer support and crisis intervention via social media. Community mental health journal. 2020; 1 .)

Reyes then responds with enthusiasm in a response, $A$ Mindfulness Mobile App for Traumatized COVID-19 Healthcare Workers and Recovered Patients: A Response to "The Use of Digital Applications and COVID-19" (https://doi. org/10.1007/s10597-020-00617-4).

This is the kind of exchange I was hoping for and I want to thank these authors for their active engagement. The remainder of the journal reflects the diversity of submissions we continue to receive from around the world. I hope readers find this issue as illuminating as I have.

Publisher's Note Springer Nature remains neutral with regard to jurisdictional claims in published maps and institutional affiliations.
Sandra Steingard

sandysteingard@gmail.com

1 University of Vermont, Burlington, VT 05401, USA 